\title{
Assessing the Efficacy and Effectiveness of an E-Portfolio Used for Summative Assessment
}

\author{
Nicole Buzzetto-More \\ University of Maryland Eastern Shore, Princess Anne, MD
}

nabuzzetto-more@umes.edu

Executive Summary

Electronic portfolios (e-portfolios) are a paradigm in constructivist e-learning. They are capable of involving students in deep learning while serving as a meaningful way for both students and faculty to engage in outcomes-based assessment. E-portfolios have been shown to be a valid way to document student progress, encourage greater student involvement in the learning process, showcase work samples, and provide a method of learning outcomes assessment and curriculum evaluation (Buzzetto-More, 2006).

This paper reports the results of a minority serving institution that has implemented an electronic portfolio project used for summative assessment as well as to encourage students to engage in deep learning and self reflection. A study was conducted that examined the students' perceptions of this project by surveying the early groups of students who completed the portfolios as seniors. According to the findings, the portfolio project helped students better understand learning goals $(88 \%)$, think about what they have learned in college (89\%), and reflect on the knowledge and skills they have developed (91\%). In addition to the surveys, rubrics used to assess student portfolios were collected and reviewed, in order to evaluate the efficacy of e-portfolios as an assessment measure with positive findings revealed.

Keywords: Electronic Portfolios, E-Portfolios, Reflection, Deep Learning, Constructivism, Assessment

\section{Introduction}

An e-portfolio is an organized compilation that demonstrates knowledge, skills, values, and/or achievements and that includes reflections or exegesis which articulate the relevance, credibility, and meaning of the artifacts presented (Cooper \& Love, 2007). They are customizable to represent the uniqueness of an individual student, requiring reflection that encourages deep learning (Barrett, 2004). Further, e-portfolios can stimulate a dialogue about learning as instructors and peers provide feedback on the portfolios engendering further action and reflection on the part of

Material published as part of this publication, either on-line or in print, is copyrighted by the Informing Science Institute. Permission to make digital or paper copy of part or all of these works for personal or classroom use is granted without fee provided that the copies are not made or distributed for profit or commercial advantage AND that copies 1) bear this notice in full and 2) give the full citation on the first page. It is permissible to abstract these works so long as credit is given. To copy in all other cases or to republish or to post on a server or to redistribute to lists requires specific permission and payment of a fee. Contact Publisher@InformingScience.org to request redistribution permission. the learner.

An e-portfolio system is a repository management system used in the creation, storage, and assessment of eportfolios. Under the name of artifacts, they are capable of including academic records, essays, project reports, assignments, audio and video files, assessments, and personal and professional development related contents linked to learning goals and reflections (Wang, 
2009). E-portfolio systems can be open source (e.g., Open Source Portfolio and Moodle's Exabis Portfolio Block), custom created by an academic institution (Purdue University's electronic portfolio system built using Microsoft's SQL and University of Singapore's Student Electronic Learning Folio developed using ASP.net), developed by an institution using open standards (e.g., Iowa's State University's eDoc), or commercially developed (e.g., eFolio, TaskStream). According to Wang (2009) among different e-portfolio systems there are significant variations in user interface design; however, regardless of platform, the functionalities of competitive e-portfolio systems are similar with all including capabilities for the uploading of artifacts, customization, commenting on and assessing student work, communicating and sharing, reflection, drawing linkages to goals, showcase generating, and varying forms of administrative reporting. Further, Wang (2009) explained that most available systems are subject independent and therefore useful across the academic spectrum.

The University of Maryland Eastern Shore (UMES), a Historically Black University, has implemented an electronic portfolio project within the Department of Business, Management, and Accounting (Department) that is used for both summative and formative assessment as well as to encourage students to engage in deep learning and self reflection. The project was initially implemented with senior standing students and was gradually embedded throughout the curriculum starting with incoming freshmen. As a multi-year project, the goal is to help both students and faculty evaluate students' academic and professional development longitudinally (Buzzetto-More, 2010). The project is designed to have several benefits:

1) Allowing both faculty and students to evaluate student growth and progression towards learning goals.

2) Encouraging students to reflect on their own growth and development.

3) Serving as a tool to guide the student in their academic and professional planning.

4) Helping students to see how course work relates to real world practice.

5) Helping students to see the interrelatedness of course learning as well as how course learning translates into their own development towards learning goals.

6) Providing a flexible assessment measure that gives students both more control and more opportunities to succeed.

7) Offering a student centered way to measure student mastery of learning goals that encourages deep learning.

8) Helping to serve as an empowerment tool by providing a mechanism for primarily first generation, low income, academically underprepared, minority learners to engage in a dialogue about their learning and accomplishments.

9) Providing a mechanism by which students can showcase their talent which can be used by students for professional promotion when looking for internships and/or permanent employment (Buzzetto-More, 2010).

Electronic portfolios are known to be effective in traditional learning environments; their use is particularly well suited to education at minority serving institutions. It is believed that e-portfolio usage compliments the mission of Historically Black Universities to open doors for students by developing student centered learning opportunities that provide students with multiple opportunities for success (Buzzetto-More, 2006).

The university represented in this study had the opportunity to pilot a prerelease of the Blackboard Portfolio system prior to full implementation. As a result, the school was an early-adopter of the first version of the system offered as an additional add on purchase to schools who had adopted the popular Blackboard Learning Management System. As with any new system, limited resources were available and those needed had to be developed by the institution. The study included in this paper examined students who had completed an electronic portfolio during the first phase of full implementation. 


\section{Literature Review}

The concept of social constructivism was defined by Vygotsky (1978) referring to an individual's construction of meaning within a social context predicated on the idea that new knowledge is built upon prior knowledge forming new cognitive structures. When applied to teaching and learning it becomes constructivism, a theoretical educational concept that suggests that learning is most effective when students are actively engaged in a learning process that involves discovery, questioning, discussion, reasoning, judgment making, and idea and opinion formation. E-learning has been cited as capable of supporting highly constructivist learning environments that are selfdirected, dependent on internal and external discourse, reflective, and problem-based (BuzzettoMore, 2006).

Perhaps, no form of e-learning is more constructivist than e-portfolio based learning (Paulson \& Paulson, 1994). Paulson and Paulson explained that "The portfolio is a laboratory where students construct meaning from their accumulated experience" (Paulson, Paulson, \& Meyer, 1991, p.5). They also explained that e-portfolio creation is a form of storytelling:

A portfolio tells a story. It is the story of knowing. Knowing about things... Knowing oneself... Knowing an audience... Portfolios are students' own stories of what they know, why they believe they know it, and why others should be of the same opinion. A portfolio is opinion backed by fact... Students prove what they know with samples of their work. (Paulson, Paulson, \& Meyer, p.2)

Ahn (2004) refers to electronic portfolios as the most effective and efficient mechanism to encourage students to reflect on their own learning processes and for teachers and peers to give feedback, which she asserts can result in the creation of a learning community. Further, the effectiveness of electronic portfolios is in the opportunity given to students to evaluate their own learning and collaborate with others while progressing toward clearly defined goals. This encourages students to engage in self-evaluation by requiring learners to examine their development, as well as their strengths and weaknesses (Corbett-Perez \& Dorman, 1999).

Speaking in anthropological terms, e-portfolios are an assemblage of artifacts that are archived. An artifact is a man-made object that was intentionally created to serve a purpose by an author (Stanford Encyclopedia of Philosophy, 1999). More specifically, an e-portfolio artifact is an electronic resource unit used to inform. According to Wang (2009) the ability of an e-portfolio artifact to inform and support learning makes it a learning object.

According to Renfrew and Bahn (1996), an assemblage is a collection of artifacts occurring in a context in order to represent an aggregate of human activities. As an assemblage, an e-portfolio also represents a purposeful collection of artifacts/learning objects representing an aggregate of human activities. Just as learning objects are stored in a learning object repository, so does the eportfolio assemblage represent a mini learning object repository unique to a particular individual or experience. Further, an institution archives multiple e-portfolios for current and future evaluation. This collection or repository of e-portfolios stored for security, preservation, and future informing then becomes a learning object repository containing the intellectual efforts of many individuals. A repository (or collection) of e-portfolios is, therefore, a social anthropological construct from which we can learn about the cognitive development of a culture or group of learners as well as the pedagogical efficacy of an institution during a period of time. They tell the story not just of the learner, but also of the learning institution.

Portfolio creation is an active learning process. According to Lorenzo and Ittelson (2005a) students creating an e-portfolio are involved in: strategic planning; the acquisition and analysis of information; processing and connection making; synthesis as they bring ideas and artifacts together, as well as designing the look and layout of their portfolio; and evaluation and self- 
reflection. Further, they explain that the skills required and processes applied in the creation of electronic portfolios help students learn, understand, and implement information literacy (Lorenzo \& Ittelson, 2005b). These concepts were further explored by Buzzetto-More (2009) in the Project Based Learning Information Literacy Model (represented in Figure 1) and the Information Literacy E-Portfolio Model (represented in Figure 2).

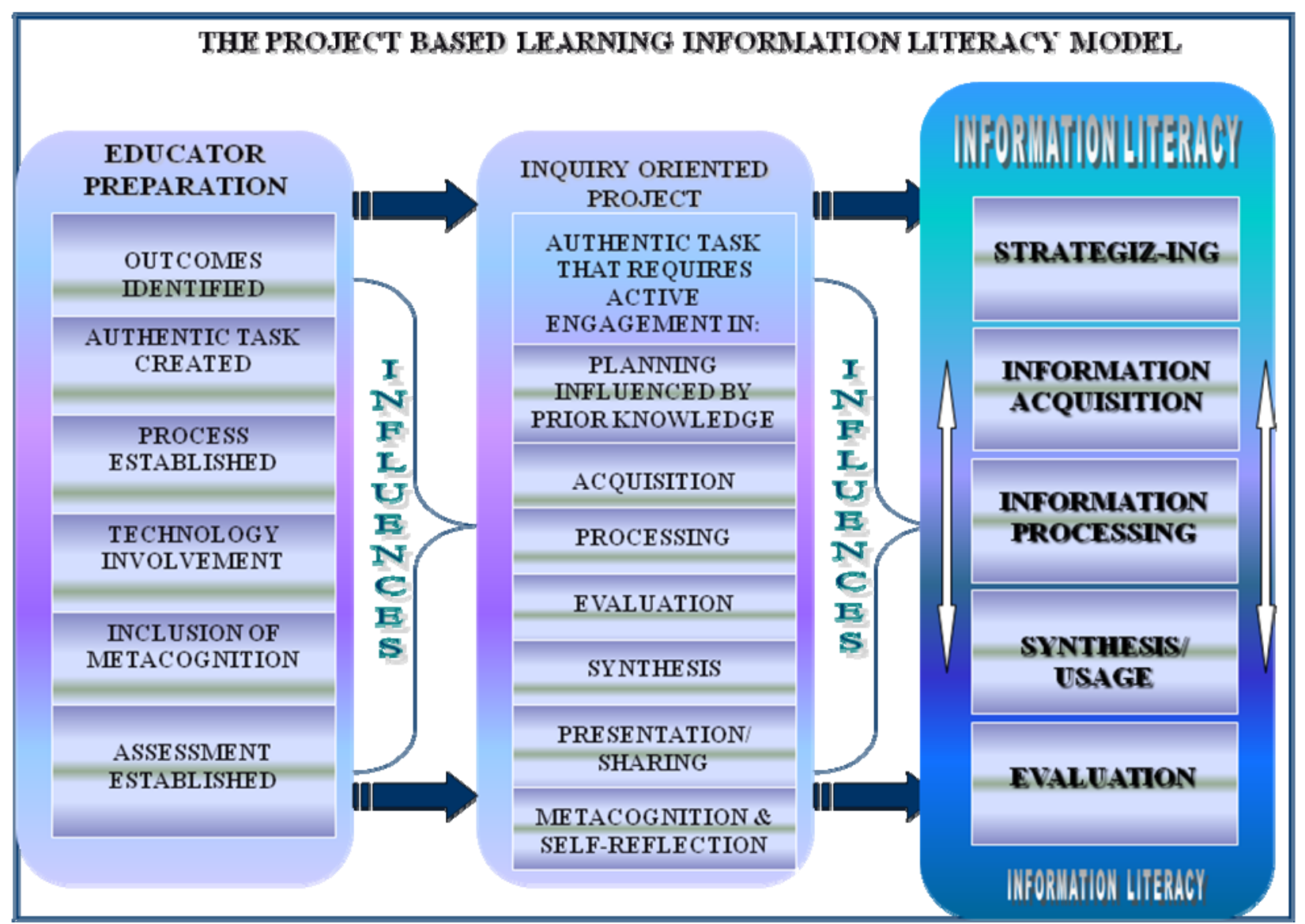

Figure 1: The Project Based Learning Information Literacy Model

As indicated in Figure 2, e-portfolio creation involves students in strategizing, acquiring information in the form of artifacts, processing that information by evaluating and making judgments about artifacts, synthesis in the compilation and development of the portfolio, meta-cognition and self evaluation through reflection authoring, articulation and discourse through presentation and sharing, and interchange through the receipt and response to feedback (Buzzetto-More, 2009). 


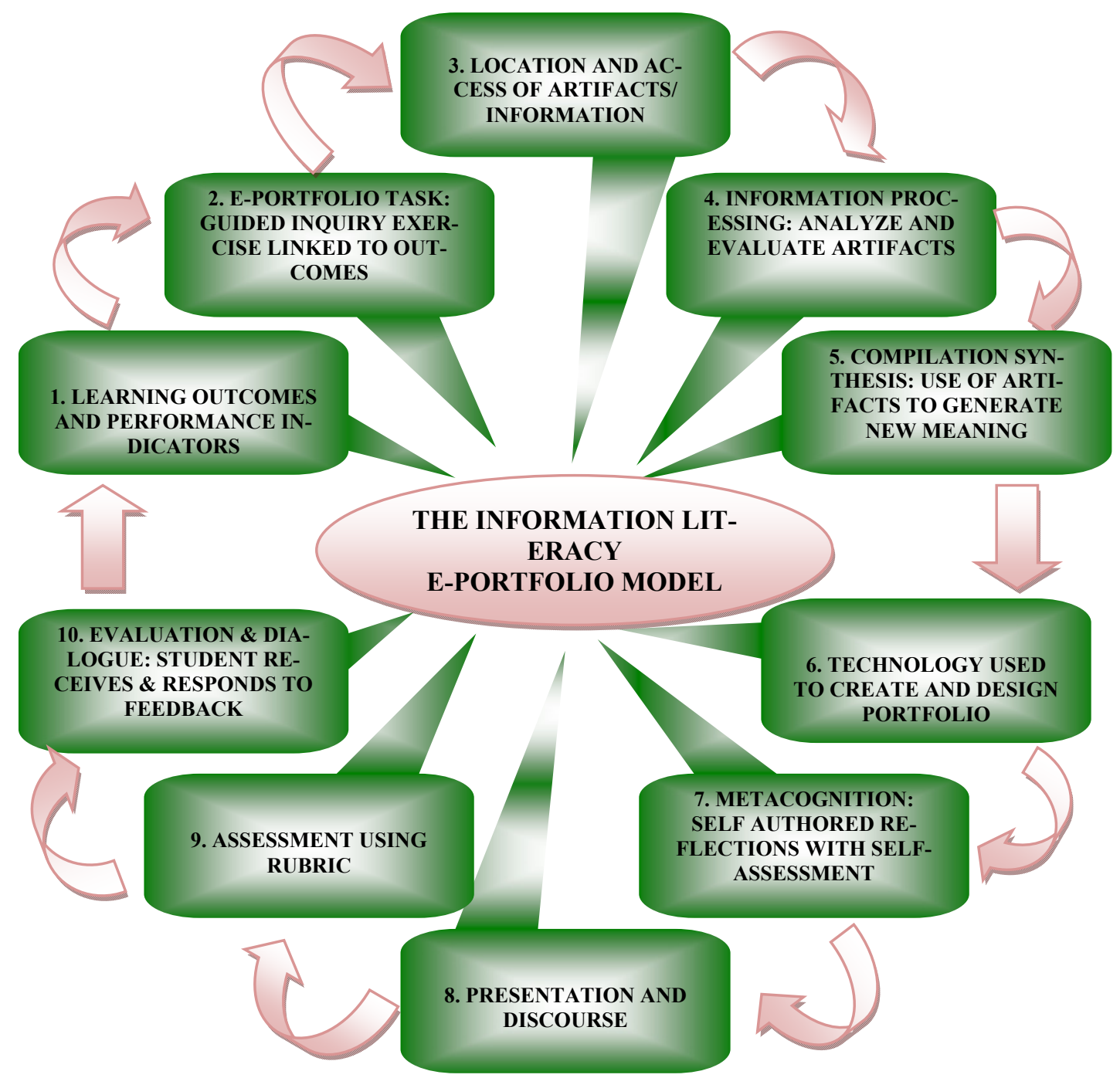

Figure 2: The Information Literacy E-Portfolio Model

A major component of e-portfolios is the inclusion of reflections. Barrett (2004) said that the reflections in e-portfolios should be guided by questions that make students consider the past while thinking towards the future. While the wording of the questions may take many forms, she suggests using a past, present, and future approach. Examples of questions worded using Barrett's approach follow:

- The Past- What have I collected about my life/work/learning via my artifacts?

- The Present- What do those artifacts show about what I have learned as articulated in my reflections on my knowledge, skills, growth, and dispositions?

- The Future- What future goals and direction do I want to take in the future?

The e-portfolio literature has extensively discussed their pedagogical efficacy. Many of these concepts are similar in nature, and since this paper is not a review of literature on e-portfolios, a selection of relevant concepts that best illustrate the pedagogical benefits of e-portfolios are summarized and presented in Table 1. 
Table 1: Pedagogical Benefits of Electronic Portfolios

Author Pedagogic Benefit

Ahn (2004)

Buzzetto-More and Alade, 2008

Cooper and Love, 2007

Cooper and Love, 2007

Cooper and Love, 2007

Cooper and Love, 2007

Venezky and Öney, 2004

Corbett-Perez and Dorman, 1999

Corbett-Perez and Dorman, 1999

Corbett-Perez and Dorman, 1999

Barrett, 2004

Paulson and Paulson, 1994

Lorenzo and Ittelson, 2005a, 2005b

Kuhlthau and Todd, 2007

Wang, 2009
Capable of creating a learning community

Authentic learning where learning is more meaningful when it is linked to real world experiences

Experiential learning where students 'learn by doing' rather than learn through telling

Competency-based education where instruction is outcomes based using electronic portfolios as part of student learning outcomes based performance assessment where assessment may include higher order skills

Lifelong learning where learning is directed by the individual and guided by the individual's interests

Autodidactism where learning is self-taught and self motivated

Active learning where students set goals for learning, engage in selfreflections, review goals, and assume responsibility for their own learning Ability to foster cooperative learning

Diagnostic in that they are capable of stimulating student strengths while simultaneously exposing them to areas needing development

Open-ended and capable of growth as students progress

Fostering deep learning that involves reflection, intrinsic motivation, story telling, interconnections, and real meaning making

Constructivist where learners construct knowledge through problem solving, collaborative discourse, evaluation

Capable of encouraging information and media literacy

Supporting of guided inquiry which involves initiation, selection, exploration, formulation, collection, presentation, and assessment

Capable of illustrating learning acquired through non-traditional or extracurricular activities

While the e-portfolio literature is quite robust in the discussion of e-portfolios and their relationship to a variety of pedagogical concepts and/or their usage as an effective authentic assessment tool, what remains sparse are relevant research findings. Needed is more research that examines, in a meaningful way, either the perceptions of students and faculty, system usage, and/or pedagogical efficacy. This paper attempts to help, albeit in a small way, to contribute to this void in the literature by presenting the results of a research study. 


\section{Background}

Beginning in 2005, as part of an aggressive assurance of learning and continuous improvement effort, the University of Maryland Eastern Shore's Department of Business, Management, and Accounting searched for a comprehensive assessment measure that was scalable and capable of growth over time. A number of options were examined and e-portfolios were selected because they have been shown to effectively provide an alternative and effective means of assessing student learning outcomes while having high acceptance rates among students (Buzzetto-More \& Alade, 2008).

A number of portfolio systems were considered and were addressed in a 2007 paper (Sweat-Guy \& Buzzetto-More, 2007) that identified, as well as compared, the pros, cons, and practical implications of a number of common platform features. Resulting from the evaluation process was the decision to adopt the Blackboard Portfolio System. This decision was made based on a review of a pre-release version of the system to which the University was granted access. The reasons behind the selection were: ease of use, interoperability and linkage with the existing course management system in use, student and faculty familiarity, the ability to invite both internal and external assessors, ease of maintenance, student rather than institutional ownership of portfolios, and the willingness of the University's Office of Information Technology to host and support the system. It is important to note, that open source systems (while considered) were not a viable option because of the institution's lack of willingness to host or support those types of systems.

Representing a sizable commitment, the e-portfolio decision making process requires both foresight and a thoughtful strategy (Buzzetto-More \& Alade, 2008). To help guide the selection, adoption, building, and implementation a model was sought. A handful of guiding questions, considerations, requisite attributes, and models were discovered and considered; however, it was noted that a comprehensive model was missing from the literature. As a result, a model was created known as the Pentagonal E-Portfolio Model, named such for its five levels, which was introduced in 2008 (Buzzetto-More \& Alade, 2008). A modified version of that model, which was published in the Journal of Information Technology Education, is presented in Table 2.

Table 2: Electronic Portfolio Development \& Implementation Model

\section{Level I: Identification of Need}

\section{Define Outcomes}

Identify Performance Indicators

Determination of Purposes (promotional, organizational development, auditing, student learning outcomes assessment, enterprise wide management, labor management, etcetera)

\section{Level II: Determination, Assessment, \& Budgeting}

\section{Selection of Features}

Assessment of Current Technology Infrastructure

Determine Portfolio Type (homegrown, open source, commercial, common tool generated like

Google Docs).

Determine Budget

\section{Level III: System Selection \& Strategic Planning}

\section{System Selection}

Development of Strategic Implementation Plan with Realistic Timeline 


\section{Level IV: Development}

Establishment of Resources

Build Portfolio Into Existing Processes

Development of Assessment Program

Level V: Implementation \& Growth

Preparing Users for Implementation

Pilot Test

Full Implementation

Longitudinal Growth and Continuous Improvement

During the summer of 2006, the Blackboard portfolio product, in agreement with the Blackboard company, was tested and used as part of a pre-pilot examination and preparation process with a group of faculty at UMES in partnership with the assistance of the UMES Center for Instructional Technology. This experience enabled some preliminary training, structuring, resource generation, and guideline formation as well as modifications to the implementation timeline.

While Blackboard had been a leader among commercial learning management systems for some time, this was the first time the company had introduced a portfolio product. And while designed to work in compliment with the Blackboard LMS, it had a number of unique attributes and, in several areas, functioned quite differently than the LMS. The most noticeable difference was the student, rather than faculty, control as well as the inclusion of a number of Web 2.0 features such as a blog and sticky note tools that were not integrated into the LMS until the release of Blackboard 9 in 2009, over 3 years later.

A rubric was developed for assessing student portfolios. The rubric was created around the Departmental learning goals, applying a four point criteria scale represented as target (10 points), acceptable ( 7.5 points), developmental ( 5 points), and unacceptable/missing ( 0 points). The performance indicators were embedded within the evaluation criteria, and a requisite score of 60 points was set as a minimally acceptable score where students earning below the 60 point cut off are required to rework and resubmit their portfolios. Overall, the rubric was designed to be comprehensive in order to ease the evaluators' assessment, to provide meaningful feedback to learners, and to generate useful data that can be aggregated/ disaggregated and analyzed for reporting and decision making.

When building the portfolio into the curriculum, it was decided that a course embedded methodology was preferred. The course that best suited the needs of the project was BUAD 495: Strategic Management which serves as the Department's capstone course. It was recognized that students should be given soft suggestions for possible portfolio artifacts, with the ultimate selection belonging to the student. With this said, it was recognized that many or most of the artifacts to be included within the portfolios would come from projects, papers, cases, plans, assignments, and etcetera that were previously assigned, submitted, and graded in key program courses. As a result, it was decided that a minimum of two artifacts would be required per learning goal and that learning goals would be assessed both for the quality of the artifacts selected and their effectiveness at demonstrating mastery as well as the effectiveness of the reflections.

Guidelines and instructions were placed within a student handbook (see sample handbook page in Figure 3). The student handbook, which was custom created for use by the Department, explained the pedagogy behind the capstone portfolio project; defined major concepts and terms; articulated the benefits to the students of outcomes-based portfolios for academic, personal, and professional usage; explained the Department's learning goals and coordinating performance indicators; pro- 
vided guidance for artifact selection; described the meanings and importance of artifacts; explained the importance of reflections as well offered guidelines for reflection generation; articulated the evaluation process; and presented the evaluation rubric. Illustrated step by step directions for usage of the system as well as useful tips and suggestions were offered. Overall, the handbook was designed to be organized purposefully and user friendly.

The student pilot occurred during the fall semester of 2007 with a group of 30 students scheduled to graduate in December of 2007. Full implementation occurred in the spring of 2008. Once full implementation occurred a survey was administered to students. This paper represents the third paper in this series and presents the results of the student satisfaction and perception survey as well as analysis of the rubric used to assess the student

Creating Reflection Topics and Posting Messages

There are two types of reflection topics:

- Blog: Create a blog (Web log) topic where users

\begin{tabular}{l} 
3 Owner Tools \\
Binders \\
Files \\
G Geflery \\
\hline 1 Reflections
\end{tabular}
post messages and contribute to an ongoing discussion where all messages are displayed on the same screen.

- Threaded: Create a threaded topic for a more structured discussion. Users post and reply to messages. Replies associated with the same post are grouped together.

Step 1: Under Owner Tools, click Reflections.

Step 2: $\quad$ Click Create Topic.

Your location: Reflections

Reflections

Create Topic Create Category

Step 3: $\quad$ Select the topic type (Blog or Threaded) and click Next.

Step 4: $\quad$ Enter a title and description

Step 5: To add the topic to an existing category, select the category. To create a category, select Create New Category and enter a name and description.

Step 6: $\quad$ Enable or disable ratings and set behavior.

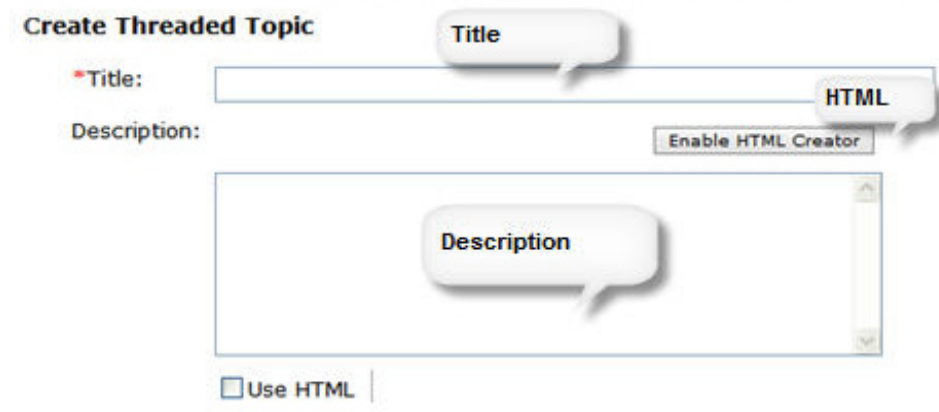

Category: Topics can be organized into categories.

Select Category: - Select -

Select 


\section{Results}

The survey was administered during the spring of 2008 as well as the 2008-2009 academic year to students following completion of the Departmental capstone course. The survey was distributed via an email message that contained a link to the survey, which was hosted on Zoomerang. In total, 147 email invitations were distributed with the survey receiving 118 visits and 106 completes, representing a response rate of $72 \%$. The respondent population was $58 \%$ female and $42 \%$ male. All majors in the Department were represented in a way that was representative of the distribution in the Department.

Most students (88\%) said that they own a computer. The same holds true for internet access; where $86 \%$ of the respondents said that they have internet access at their current residence. Prior experience with electronic portfolios was examined. While e-portfolios had already been embedded in several lower level courses in the curriculum, many of these students had taken those courses prior to participating in this study. As a result, $85 \%$ of students said that this was their first time creating an electronic portfolio.

When students were asked where they were most likely to access the portfolio system, the most common response was "At School" (79\%) followed by "At Home" (19\%). Amount of time spent per week working on the portfolio was examined. According to the respondents, most students said that they spent either 1-2 hours a week (37\%), or 3-5 hours per week (35\%) working on the portfolio. Only $25 \%$ of students said that they spent more than 9 hours a week working on the portfolio with 3\% saying that they did not spend any hours a week working on the portfolio.

By and large, the students were not familiar with the learning goals of the Department of Business prior to beginning their work on the portfolio (13\%) with 58\% saying that they were not familiar and $29 \%$ saying that they were somewhat familiar.

A series of five point Likert-scale questions were asked in order to measure student agreement to statements. When asked to respond to the statement "I enjoyed creating the portfolio" the responses indicated a high level of agreement, with $69 \%$ of respondents either agreeing or strongly agreeing, with $24 \%$ saying neutral/undecided, and with $7 \%$ disagree/strongly disagreeing (see Figure 4).

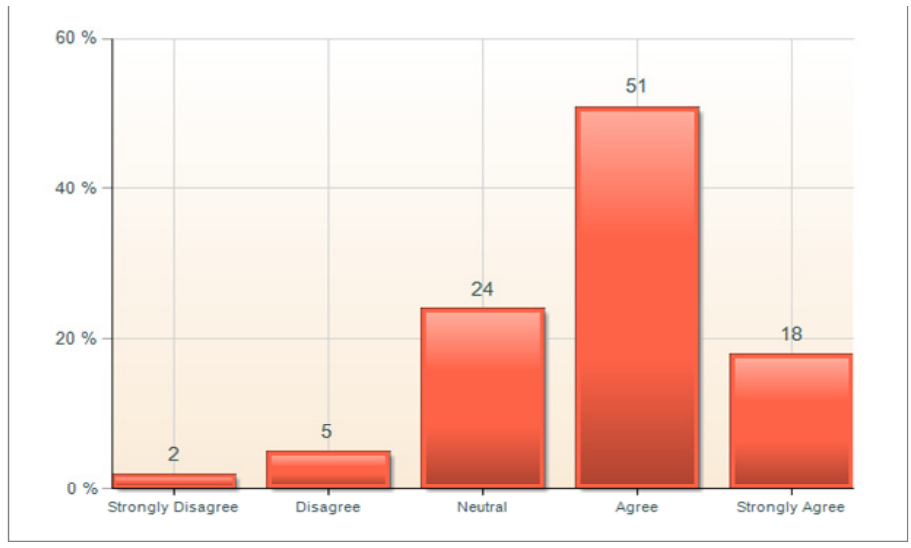

Figure 4: I enjoyed creating the portfolio

When asked whether the portfolio building process encouraged them to think about what they have learned during their time in the Department, an overwhelming $89 \%$ of respondents agreed/strongly agreed with $8 \%$ neutrality and 3\% disagreement. These results are shown in Figure 5. 


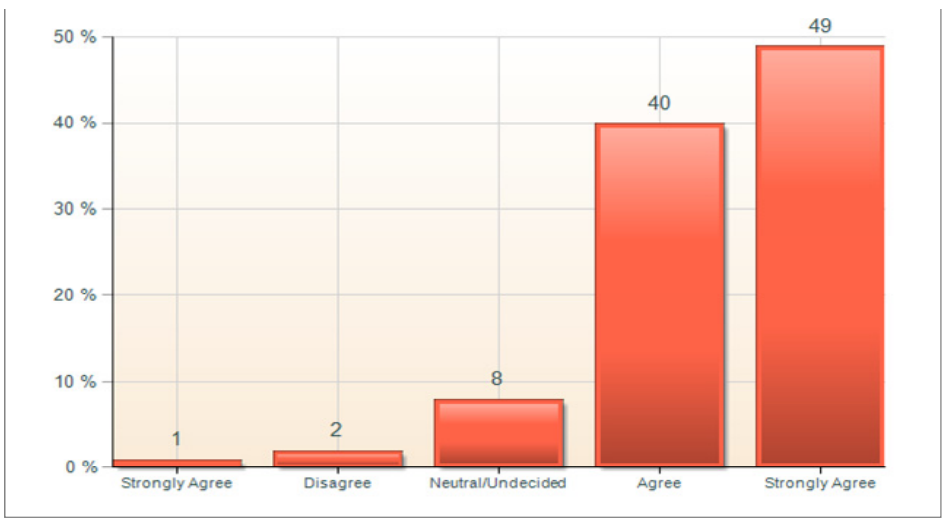

Figure 5: Portfolio Building Encouraged me to Think About What I have Learned

Most students (88\%) either agreed or strongly agreed to the statement, "The portfolio building process encouraged me to think about the student learning goals of the UMES Department of Business" with 10\% neutrality and 2\% disagreement. These results are depicted in Figure 6.

\section{Department}

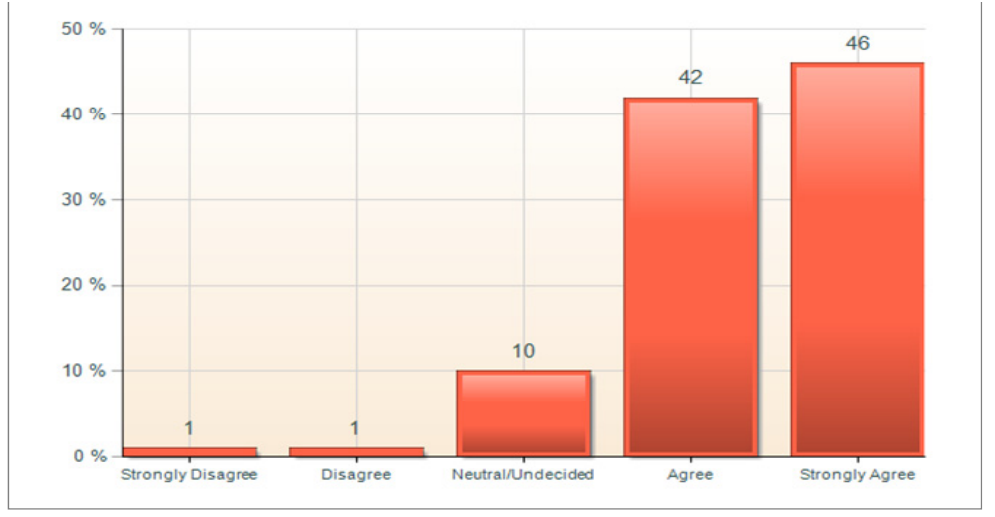

Figure 6: The portfolio building process encouraged me to think about the student learning goals of the UMES Department of Business

A major goal of electronic portfolios is self reflection where students reflect upon their development during their time in a degree program. As a result, very strong agreement (91\%) to the statement, "The portfolio building process encouraged me to think about the professional knowledge, skills, and abilities I have acquired" was not surprising and is shown in Figure 7. 


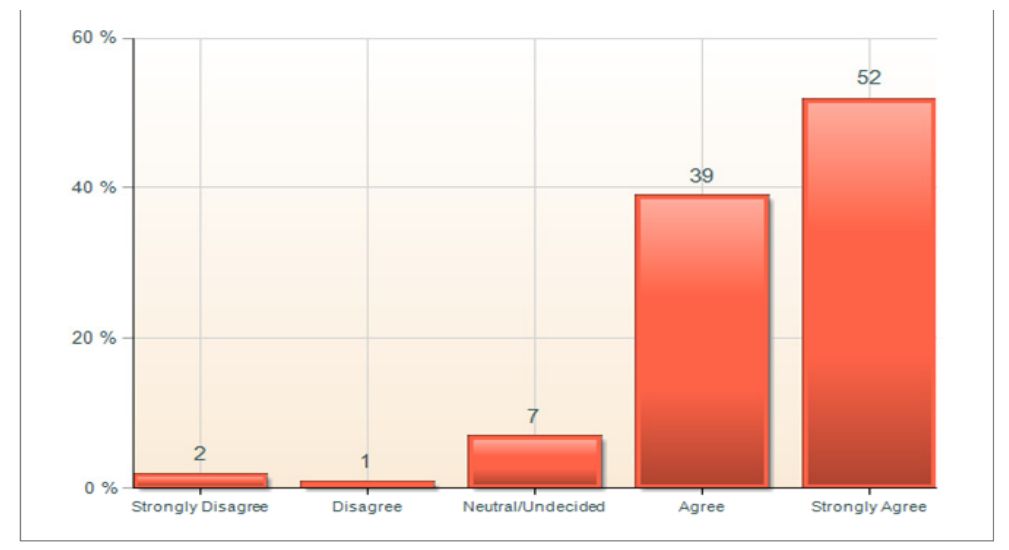

Figure 7: The portfolio building process encouraged me to think about the professional knowledge, skills, and abilities I have acquired

The portfolio project has been designed not just to be used for assessment and reflection but also for professional promotion. To help accomplish this goal, the portfolios are owned by, and available to, students for a period of 10 years following graduation. Because students retain ownership and accessibility options, they are able to invite and control access by individuals who are both internal and external to the institution. As a result, students were asked whether they may show their electronic portfolio to potential employers with $76 \%$ agreeing/strongly agreeing, $16 \%$ responding neutral/undecided, and 8\% disagreeing (see Figure 8 ).

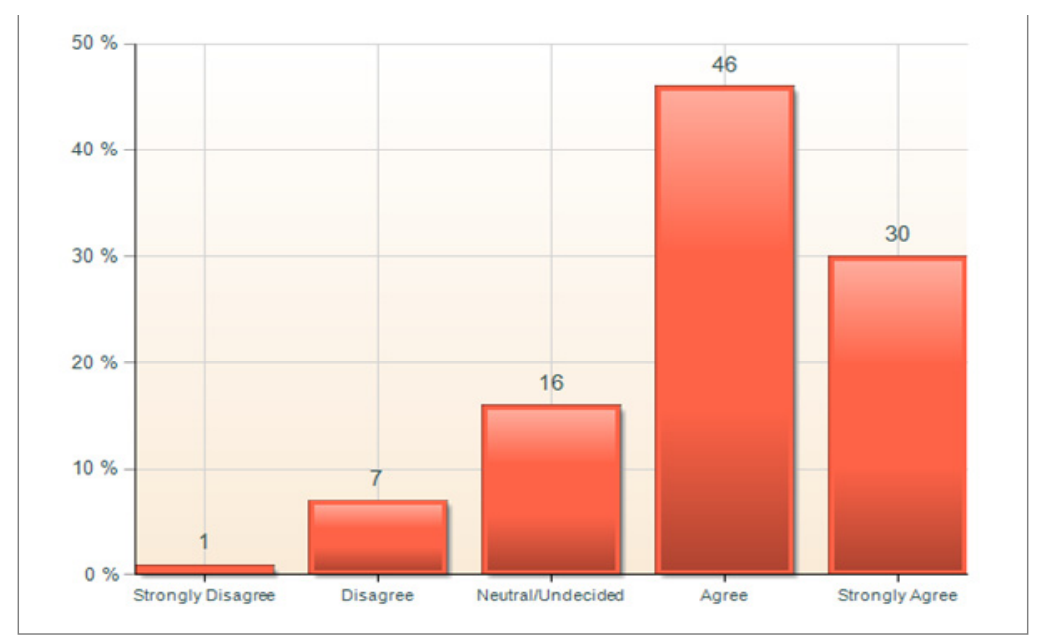

Figure 8: I May Show My Electronic Portfolio to Potential Employers

The Department was unsure whether the students felt that the portfolio building process helps in the development of organizational skills; however, when asked, $83 \%$ of respondents agreed/strongly agreed that electronic portfolios encourage people to develop organizational skills with $10 \%$ neutrality and $7 \%$ disagreement. These results are shown in Figure 9. 


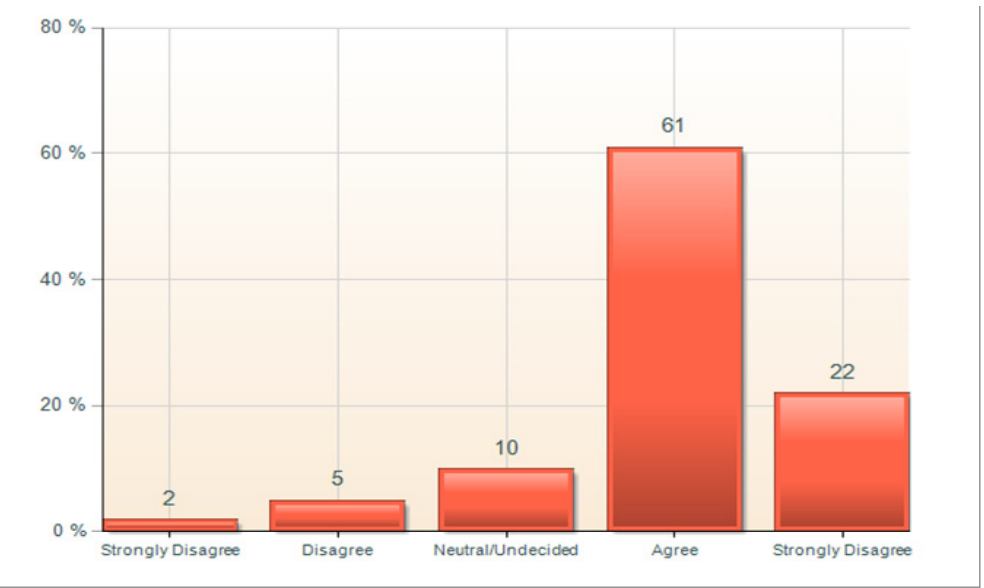

Figure 9: Electronic Portfolios Encourage People To Develop Organizational Skills

Most students (89\%) agreed/strongly agreed that electronic portfolios are a good way for students to showcase their talents with $8 \%$ neutrality and 3\% disagreement. These results are shown in Figure 10.

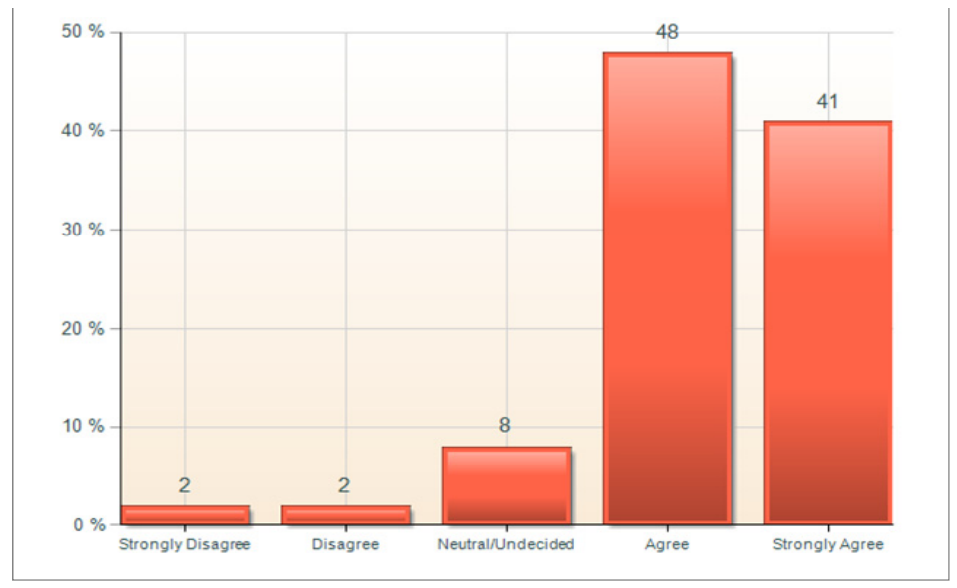

Figure 10: Electronic Portfolios are a Good Way For Students to Showcase Talents

A major thrust to the e-portfolio movement is e-portfolios' ability to encourage self reflection and critical thinking. Students were asked whether electronic portfolios encouraged them to think critically about what they have learned in college and $89 \%$ agreed/strongly agreed with $7 \%$ neutrality and 5\% disagreement (see Figure 11). 


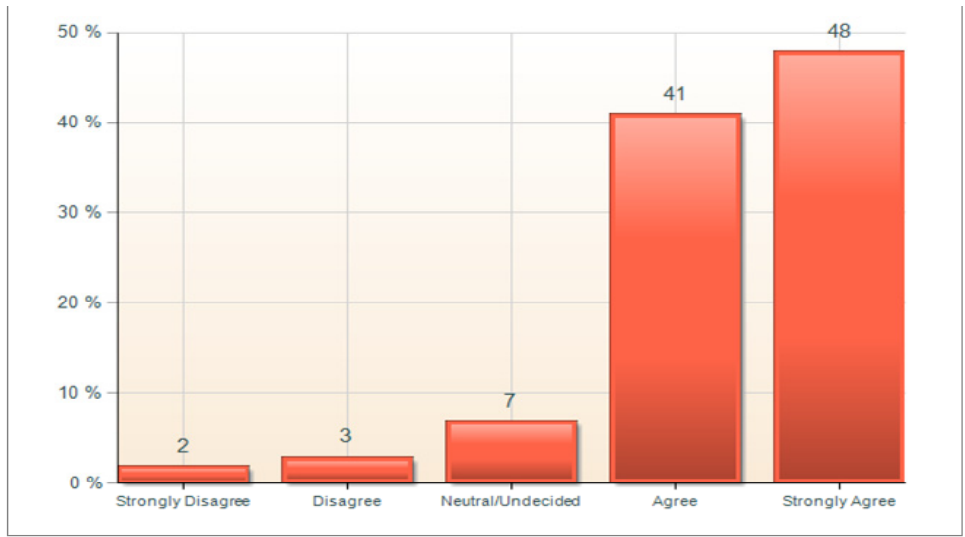

\section{Figure 11: E-Portfolio Encouraged Me To Think Critically About College}

Whether students perceive the e-portfolios as having benefits was examined. The majority of students $(88 \%)$ agreed/strongly agreed that there are benefits to student created electronic portfolios with 9\% neutral/undecided and 3\% disagreement (see Figure 12).

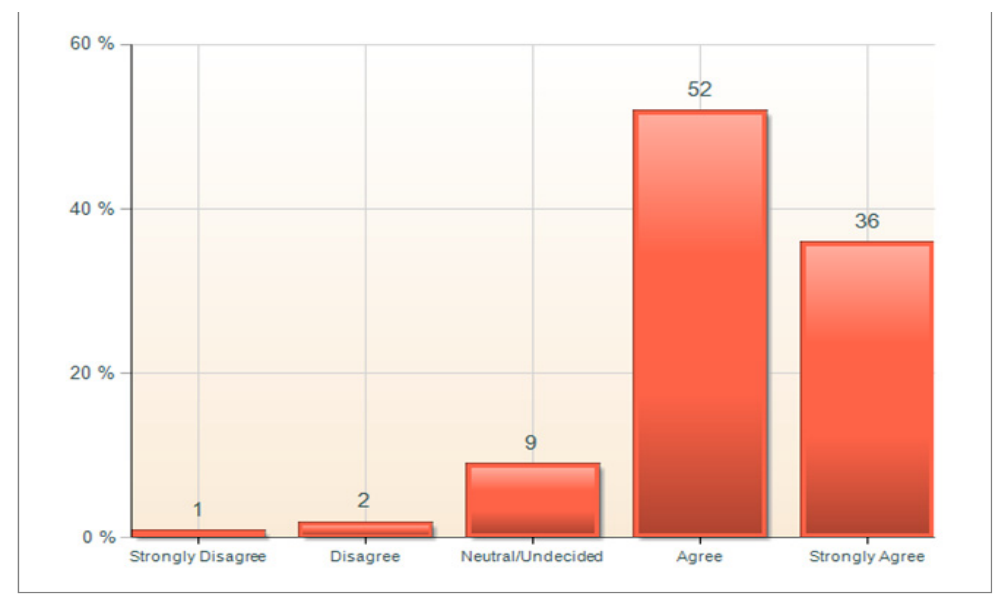

\section{Figure 12: I Feel That There Are Benefits to Student E-Portfolios}

When asked to respond to the statement, "I found the portfolio system easy to use," students were largely in agreement. According to the responses, $61 \%$ agreed/strongly agreed with $30 \%$ being neutral or undecided and 9\% disagree/strongly disagreeing.

Ease of use, usability, support, and difficulties were examined with a series of questions. According to the students, most ( $75 \%$ ) felt supported during the portfolio creation process, $80 \%$ found the student manual to be a useful resource, $57 \%$ said that they did not have difficulties selecting portfolio artifacts, and 58\% did not have difficulties authoring reflections. The results for all of these questions are shown in Table 3.

\section{Table 3}

\begin{tabular}{|c|c|}
\hline Strongly Disagree & $3 \%$ \\
\hline Disagree & $3 \%$ \\
\hline Neutral/Undecided & $19 \%$ \\
\hline
\end{tabular}




\begin{tabular}{lc|} 
Agree & $44 \%$ \\
\hline Strongly Agree & $31 \%$ \\
\hline Total & $100 \%$ \\
\hline $\begin{array}{l}\text { The student portfolio manual was a useful re- } \\
\text { source. }\end{array}$ \\
\hline Strongly Disagree & $2 \%$ \\
\hline Disagree & $1 \%$ \\
\hline Neutral/Undecided & $18 \%$ \\
\hline Agree & $42 \%$ \\
\hline Strongly Agree & $38 \%$ \\
\hline Total & $100 \%$ \\
\hline
\end{tabular}

\section{I did NOT have difficulties selecting artifacts for} my portfolio

\begin{tabular}{lc}
\hline Strongly Disagree & $4 \%$ \\
\hline Disagree & $12 \%$ \\
\hline Neutral/Undecided & $26 \%$ \\
\hline Agree & $42 \%$ \\
\hline Strongly Agree & $15 \%$ \\
\hline Total & $100 \%$
\end{tabular}

I did NOT have difficulties authoring reflections.

\begin{tabular}{lc}
\hline Strongly Disagree & $2 \%$ \\
\hline Disagree & $8 \%$ \\
\hline Neutral/Undecided & $33 \%$ \\
\hline Agree & $49 \%$ \\
\hline Strongly Agree & $9 \%$ \\
\hline Total & $100 \%$ \\
\hline
\end{tabular}

Since the Department had always planned on introducing the portfolio earlier on during students' academic experience, it was important to find out from students where they thought the portfolio should be introduced to students. According to the students, 33\% said that freshmen year is the ideal time, with $29 \%$ saying sophomore year, $15 \%$ junior year, and $22 \%$ senior year.

Students were asked to respond to three open ended questions. These responses were tagged, categorized, and analyzed. When asked the question, "What do you see are the benefits to the student portfolios?" the most common responses dealt with the showcasing or presenting of skills and talents $(31 \%)$, followed by organization (19\%), professional usage $(17 \%)$, and the ability to engage in self reflection (16\%). These results are shown in Table 4. 


\begin{tabular}{lc}
\hline \multicolumn{2}{c}{ Table 4} \\
Tagged results for: What do you see are the benefits to the student portfolios? \\
\hline Showcase, skills, shows, presents, proof, skills, talents & $31 \%$ \\
\hline Organizes, organization, one location & $19 \%$ \\
\hline employers, employment, jobs, professional & $17 \%$ \\
\hline reflect, reflections, recaps, reminds & $16 \%$ \\
\hline Other & $33 \%$ \\
\hline
\end{tabular}

When asked about the drawbacks to student portfolios, the most common responses were that they are time consuming (28\%), followed by difficulties with system usage or a lack of guidance $(12 \%)$ and problems with locating resources/artifacts (11\%). Interestingly, $21 \%$ said that there were no drawbacks (see Table 5).

\section{Table 5}

Tagged results for: What are the drawbacks to student portfolios

\begin{tabular}{ll}
\hline time consuming, long & $28 \%$ \\
\hline difficult, lack of guidance, system usage, directions & $12 \%$ \\
\hline finding, locating, did not save, lost & $11 \%$ \\
\hline none, nothing & $21 \%$ \\
\hline Other & $34 \%$
\end{tabular}

Students were asked to provide the Department with guidance for improving the portfolio process for future students. While these responses were more difficult to tag, the most common responses were introduce sooner/earlier (29\%), give more directions/instructions/guidance (22\%), make the system easier (7\%), and other (44\%). These responses are shown in Table 6.

Table 6

\begin{tabular}{|c|c|}
\hline earlier, sooner & $29 \%$ \\
\hline directions, instruction, guidance, examples & $22 \%$ \\
\hline make system easier & $7 \%$ \\
\hline Other & $44 \%$ \\
\hline
\end{tabular}

\section{Analysis of Student Rubrics}

All electronic portfolios are assessed using a rubric that was specifically built to examine students' ability to bring in artifacts and author reflections to demonstrate mastery and understanding of the seven learning goals of the Department. The rubric applies a four point criteria scale represented as target, acceptable, developmental, and unacceptable/missing. While all student portfolios are assessed, a sample was taken from the Spring of 2009 when approximately 25 port- 
folios were examined by a team that ranged from between 3-5 individuals representing multiple business disciplines. While no pre-portfolio rubric data is available for comparison, the information collected provides both baseline information for the project in its earlier stages, anecdotal evidence, and information regarding the percentage of students who have hit performance goals.

Learning Goal I dictates that graduates should think critically and solve problems strategically. When assessing this learning goal the artifacts and reflections should illustrate that the student is able to analyze situations \& problems, differentiate $\&$ discriminate while making judgments based on a variety of given criteria, evaluate these judgments, formulate \& organize plans, make predictions, evaluate results, make revisions as needed, \& support their ideas. When learning Goal I was examined $29 \%$ of students had artifacts and reflections that were on target, $49 \%$ were acceptable, 20\% developmental, and 2\% unacceptable. These results are shown in Figure 13.

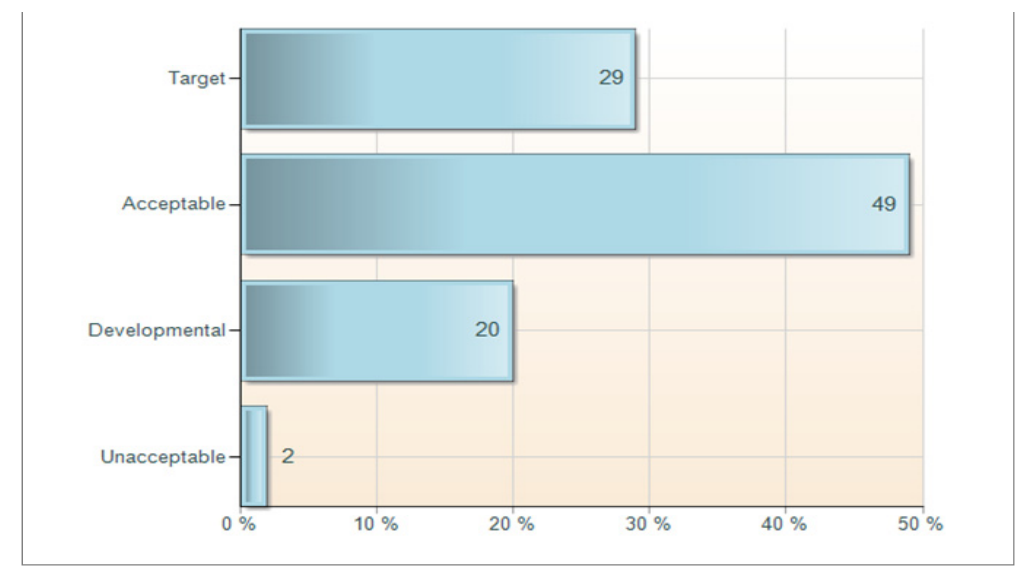

Figure 13: Learning Goal I Graduates should think critically and solve problems strategically

Learning Goal II, which deals with the communication skills of students, was assessed. When assessing this learning goal the artifacts and reflections should clearly indicate that the student can select the appropriate medium to deliver a message, support ideas factually, communicate clearly and concisely, make meaningful connections, make professional presentations, apply proper verbal and nonverbal communication techniques, and develop thesis statements. The artifacts and reflections should show that the student's writing is correctly and appropriately formatted; free of grammatical and mechanical errors; and professional in tone, structure, word choice, organization, and content. When the rubric was analyzed $22 \%$ of students reached target, $42 \%$ were acceptable, $35 \%$ developmental, and $2 \%$ unacceptable (see Figure 14). It is interesting to note that while students complete an e-portfolio in the required course, business communications, designed to specifically satisfy this learning goal, not all students elected to use the portfolio as one of their artifacts. 


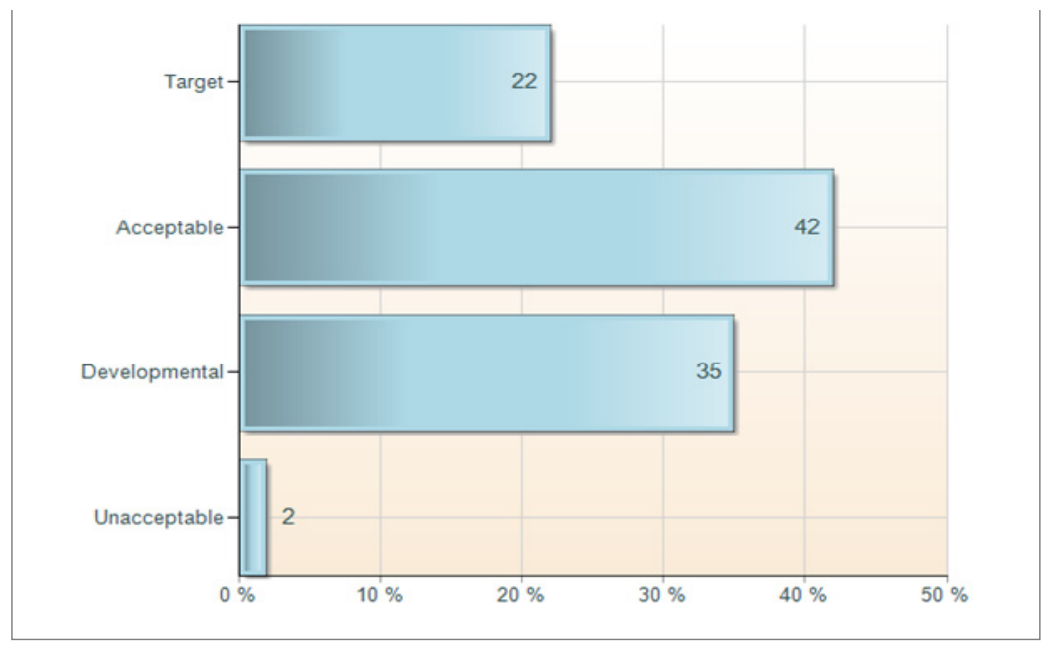

Figure 14: Learning Goal II Communications

Learning Goal III considers quantitative skills. Artifacts and reflections should illustrate that the student is able to use a variety of quantitative computational methods to collect, construct, and assemble ideas; analyze, discriminate, compare, contrast, and estimate; make predictions; formulate ideas and construct plans; and evaluate and support concepts. The results showed that $18 \%$ of students were target, $44 \%$ acceptable, $25 \%$ developmental, and 13\% unacceptable. These results are shown in Figure 15.

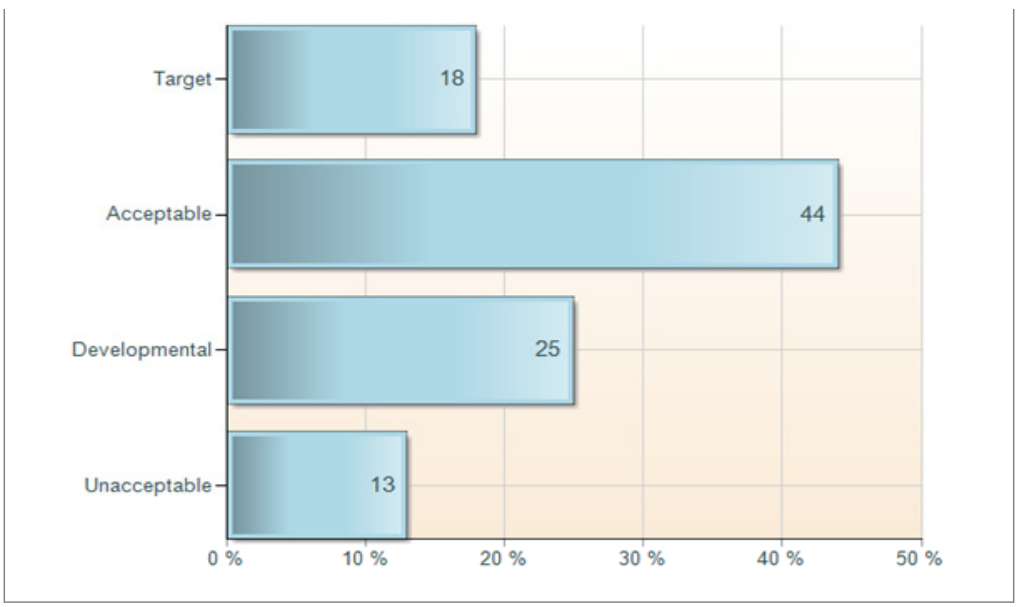

Figure 15: Learning Goal III Quantitative Skills

Learning Goal IV deals with the ethical, legal, multicultural, collaborative, and socially conscious knowledge of students. Artifacts and reflections should indicate that, from a global, diversity aware, and historically conscience perspective, the student can identify, analyze, evaluate, and reflect upon ethical, legal, socially responsible behaviors, cases, and decisions for both personal and corporate citizenship. When assessed, 19\% were target, 34\% acceptable, $40 \%$ developmental, and $8 \%$ unacceptable (see Figure 16). 


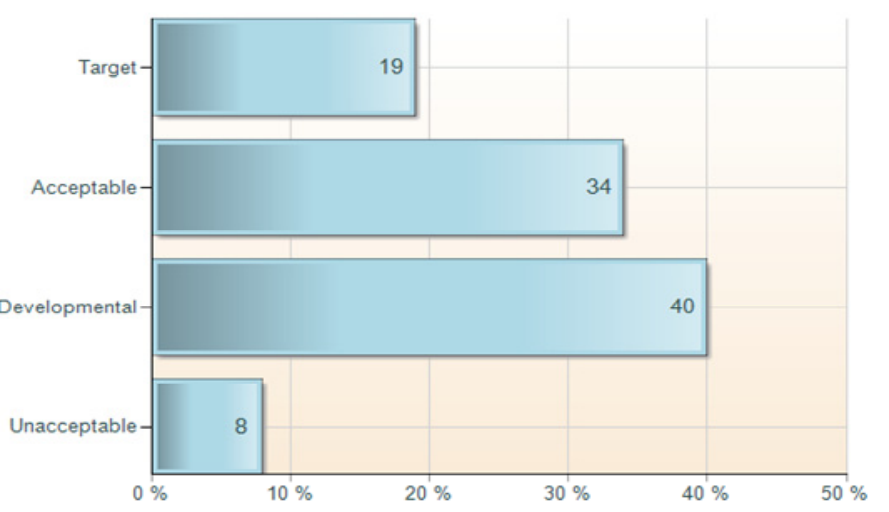

Figure 16: Learning Goal IV From a global and historical perspective graduates should be able to reflect upon ethical and socially responsible behavior, diversity, leadership, and group dynamics.

Learning Goal V assesses the technological literacy of students where artifacts and reflections should show that a student can identify the essential components of a computer system and distinguish between system and software usage; define and the basic components of a database; identify and define basic internet terminology and activities; define major networking terms and identify basic network structures; utilize Microsoft Word to create and edit documents, author reports and newsletters, merge documents, create mailings and labels, create websites, and create tables and charts; utilize Microsoft Excel to create and edit spreadsheets, manage large notebooks, create and print graphs, create and edit pivot tables and pivot charts, create conditional statements, conduct sorts, and filters, and perform audits; use Microsoft Access to create and manage databases, prepare queries, develop forms, and prepare custom reports; create presentations in PowerPoint with embedded graphics and links; discuss different types of information systems; use Microsoft Outlook to send, organize, compose, edit, and merge messages, send meeting requests; and use search services to locate and evaluate resources.

Students build an electronic portfolio in an intermediate information systems course that is designed to satisfy all technology goals of the Department. Many of the students completing these portfolios had taken the course prior to the implementation of the electronic portfolio and were thus unable to embed a previously created portfolio into their capstone portfolio. As a result, the scores are not as high as it is anticipated they will be in the near future with $17 \%$ target, $45 \%$ acceptable, 34\% developmental, and 4\% unacceptable (see Figure 17).

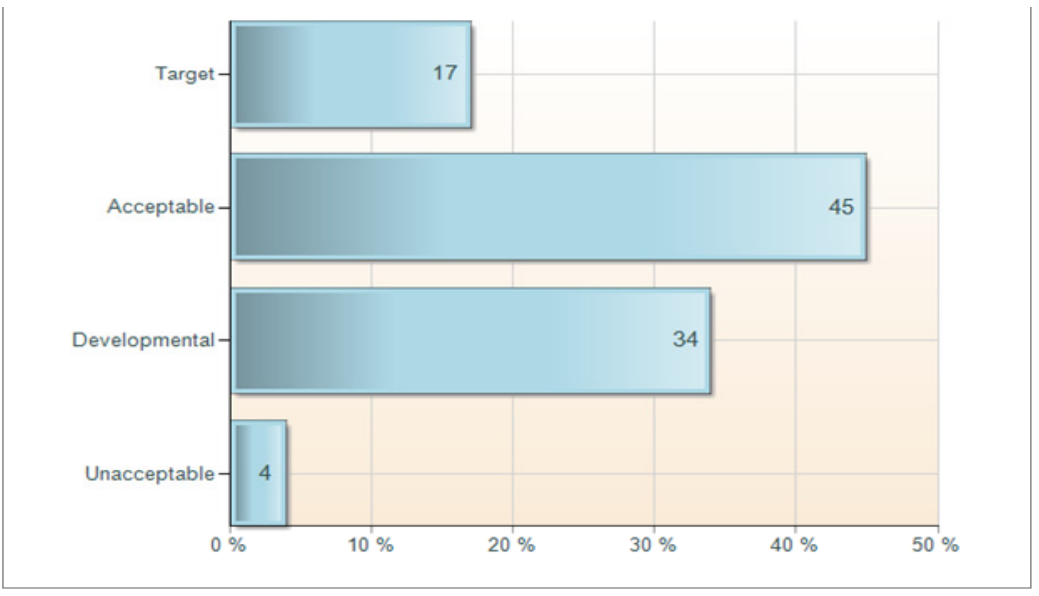

Figure 17: Learning Goal V Technological Literacy and Information Systems Proficiency 
The portfolios were examined for artifacts and reflections that indicate solid foundational knowledge of the business core functional areas including: accounting, finance, economics, management, and marketing as well as the significant theories, principles, and concepts pertaining to each of these areas. When examined, 19\% reached target, $43 \%$ were acceptable, $34 \%$ developmental, and 4\% unacceptable. These results are depicted in Figure 18.

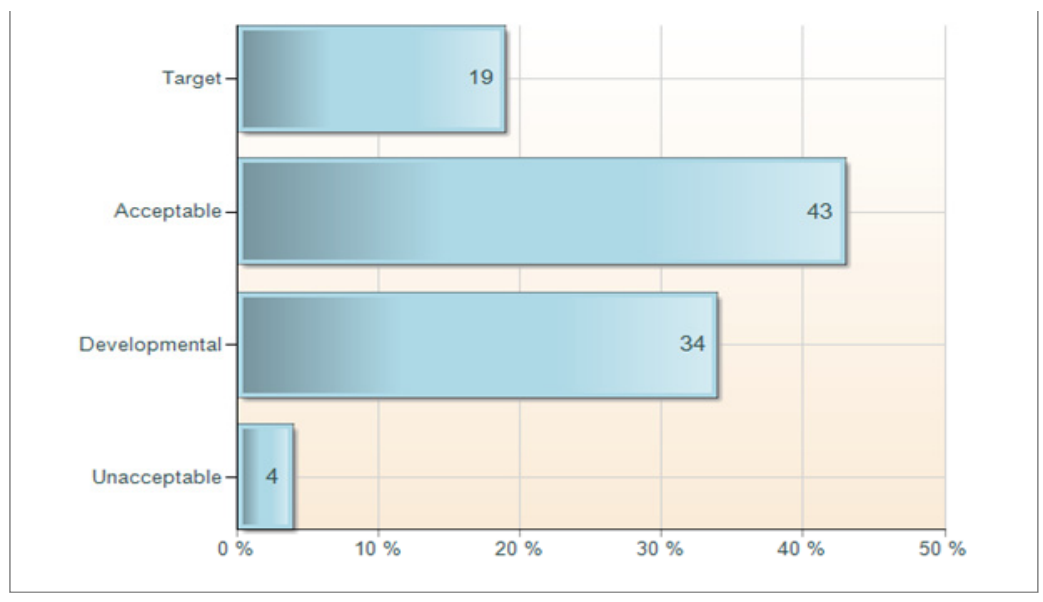

Figure 18: Learning Goal VI Knowledge of the business core functional areas

The final learning goal of the Department requires that students have comprehensive knowledge, skills, and professional orientation for productive careers and graduate study. This was the goal which the students were the most successful at satisfying with 35\% reaching target, 33\% acceptable, 29\% developmental, and 4\% unacceptable (see Figure 19).

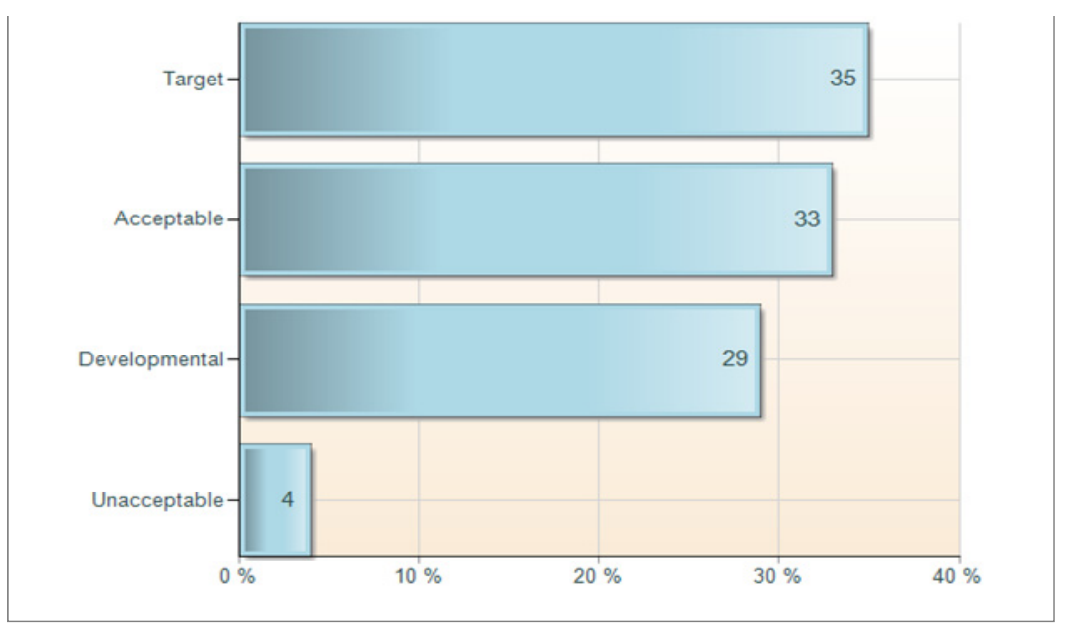

Figure 19: Learning Goal VII Professional orientation

In addition to the learning goals the students' ability to reflect is also a consideration. Students were given guidelines for authoring reflections, and reflections were examined based on the student's ability to author appropriate and complete reflections for each artifact that answer the following questions: why each artifact was chosen; which learning goal(s) they help to satisfy; how they help to satisfy learning goal(s); weakness and strengths of the artifacts selected; how the learning goal relates to the student's professional /or personal goals and plans; learning processes 
involved with the student's development of the learning goal; and future plans with respect to learning goals under consideration. Reflections were also examined for appropriateness in length, organization, use of complex sentence structures, grammar, effective language, and expression of ideas. The assessment of the reflections indicated that $20 \%$ were target, $35 \%$ acceptable, $41 \%$ developmental, and 4\% unacceptable (see Figure 20). Since the ability to reflect was a foreign experience to these students, as well as an activity that requires higher order thinking and metacognitive behavior, it was expected that the reflections would receive the lowest score among any of the rubric components.

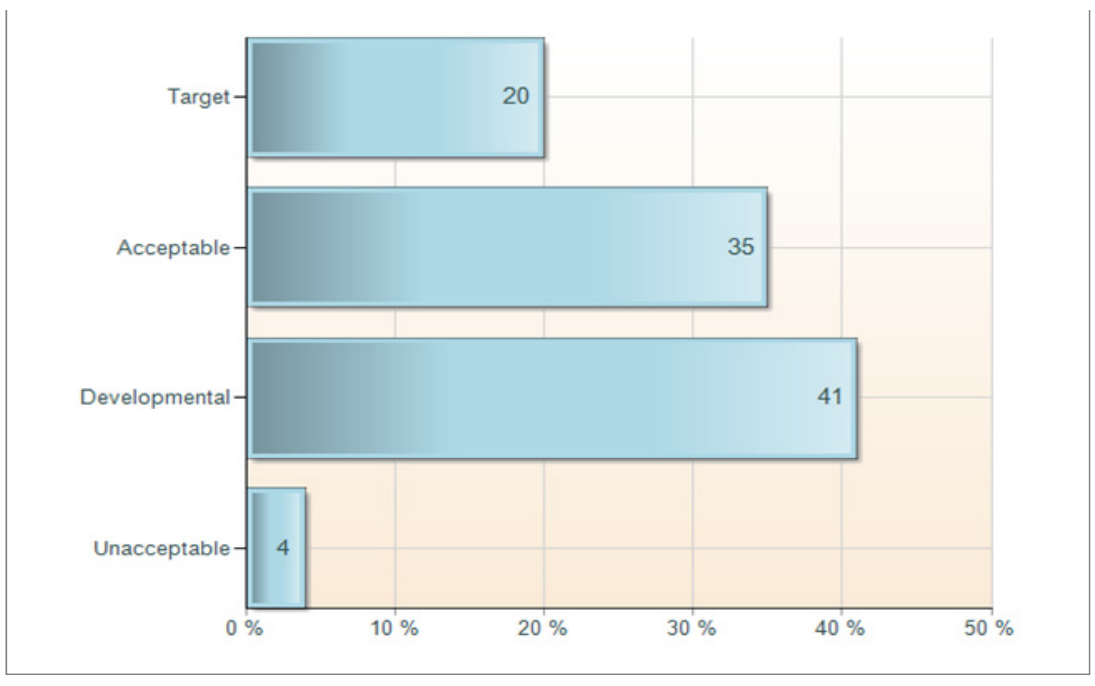

Figure 20: Reflections

The overall appearance, design, and professional presentation of the portfolios were considered based on design, style, appropriateness, ease of navigation, clarity, and sophistication with $18 \%$ target, $51 \%$ acceptable, $27 \%$ developmental, and $4 \%$ unacceptable. These results are depicted in Figure 21.

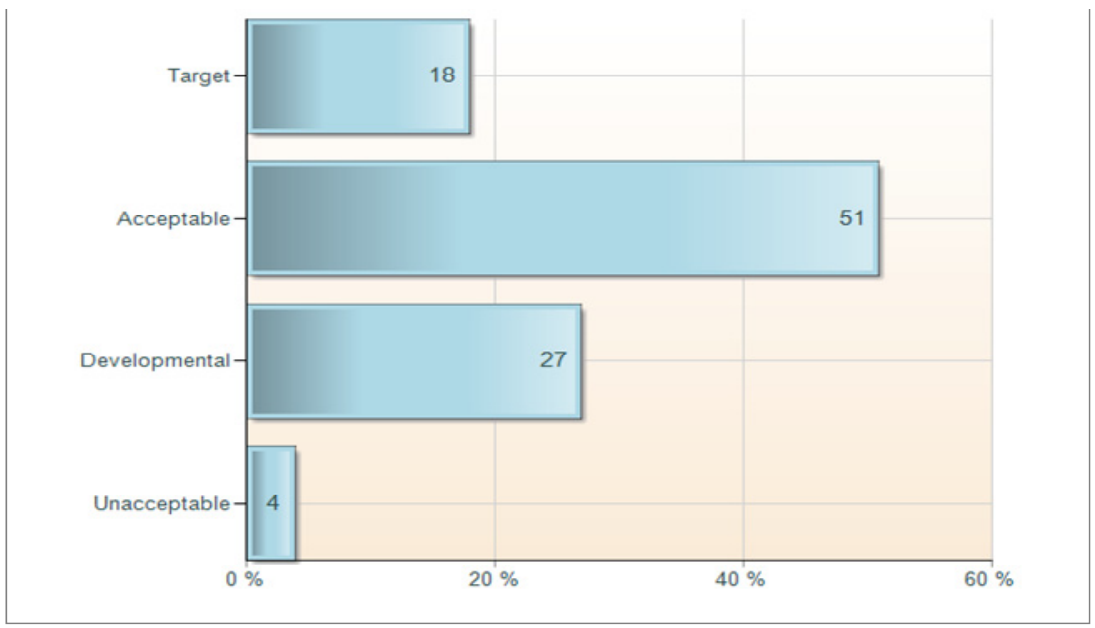

Figure 21: Appearance and Design

Finally, the quality, completeness, and professionalism were examined with $18 \%$ target, $40 \%$ acceptable, 40\% developmental, and 2\% unacceptable. These results are shown in Figure 22. 


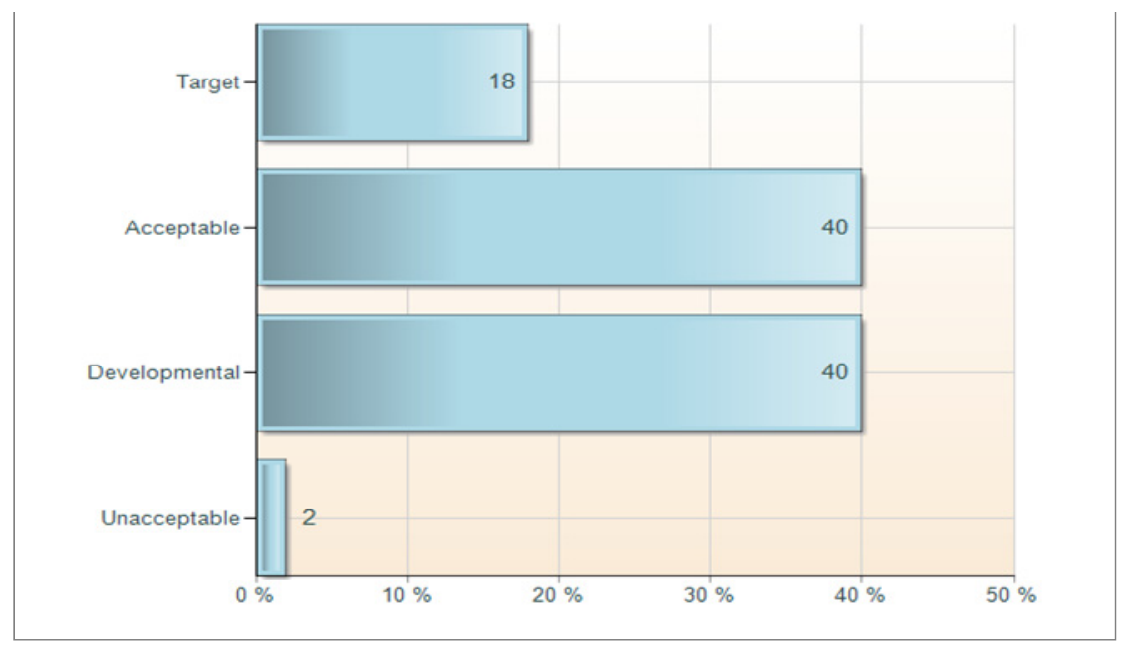

Figure 22: Quality/Completeness/Professionalism

The students included within this study represented the first groups to complete the senior capstone electronic portfolios following full implementation. As a result, the portfolios varied in their quality with not all of the initial students taking the project seriously and with no examples of exemplary student work available for student consideration. As a result, the Department anticipated that only half of the students would score either target or acceptable on each of the criteria being accessed on the rubric. Following the analysis of the rubric, the following target/acceptable rates were achieved:

- $\quad$ Learning Goal I-78\%

- $\quad$ Learning Goal II- 64\%

- $\quad$ Learning Goal III- $62 \%$

- $\quad$ Learning Goal IV- 53\%

- $\quad$ Learning Goal V- $62 \%$

- Learning Goal VI- $62 \%$

- $\quad$ Learning Goal VII- 68\%

- $\quad$ Reflections- 55\%

- Overall Appearance-78\%

- Quality and Professionalism- 68\%

These results were higher than anticipated and, therefore, considered positive, as student performance in electronic portfolio projects is usually low in the beginning with increasingly more positive results as the project matures and becomes more an integral part of the academic culture with a more perfected methodology for support and training. Overtime, as experience and comfortability increases it is expected that scores on all rubric components will rise. The rubric data analyzed showed that students completing these early portfolios exceeded the expectations of the Department.

As another means of analysis, the surveys of the 25 students whose portfolios were examined were considered. While, the information gleaned is anecdotal, a correlation was found between low student scores and negative perceptions of the e-portfolio experience. Students who had un- 
acceptable scores due to missing and/or ineffective artifacts or components and/or who exhibited a lack of effort were more likely to perceive the e-portfolio experience negatively.

With respect to the efficacy of the e-portfolios as a mechanism for evaluating student completion of departmental learning goals, the five evaluators as well as the Departmental Assurance of Learning Committee were questioned. It was unanimously agreed that the artifacts and reflections included within the portfolios provide both an accurate reflection of an individual student's progression towards completion of learning goals as well as his/her particular strengths and weaknesses. At the same time, the faculty noted that some student projects that would serve as meaningful artifacts were consistently omitted by students. To remedy this, a very detailed chart that aligned the learning goals with specific possible artifacts developed in both business and general education courses was established.

Additionally, in order to enhance the quality of the student portfolios several decisions were made:

- implementation earlier in the students' academic experience,

- greater project weight in the courses were the portfolio is embedded,

- more time provided to students to complete portfolios,

- greater guidance, and

- the embedding of more reflections across the curriculum.

\section{Limitations}

This study represents the perceptions and performance of students enrolled at a single institution. As a result, the results reported are unlikely to have a broader application. Unfortunately, because of the uniqueness of this project, it was not possible for the researchers to expand this study beyond the current population. Additionally, no pre-portfolio rubric data was available for comparison.

\section{Conclusions and Future Work}

This paper presented the results of a survey that examined student perceptions of a senior capstone portfolio project.

According to the findings, most students (69\%) said that they enjoyed creating the portfolio and that there are multiple benefits to student created portfolios (88\%); almost all students $(89 \%)$ agreed that the portfolio encouraged them to think about what they had learned during their academic experience, and students affirmed that the portfolio building process encouraged them to think about the professional knowledge, skills, and abilities they acquired (91\%). When the results of the rubric assessment were examined the portfolios were found to be of varied quality; however, student performance was found to be better than had been anticipated where the majority of students scored either target or acceptable on all criteria being accessed by the rubric.

Encouraged by the results of the research study as well as positive feedback received from faculty, the UMES Department of Business, Management, and Accounting decided to move forward with its plan to expand the portfolio project to a multi-year, interdisciplinary effort. As a result, in the Fall of 2009 the portfolio was introduced and embedded into the freshmen, sophomore, and junior professional development courses with its place in the senior capstone course remaining.

The following benefits were identified in support of the decision: (a) e-portfolios allow both faculty and students to evaluate student growth and progression towards learning goals; (b) eportfolios help students to see how course work relates to real world practice; (c) e-portfolios help 
students to see the interrelatedness of course learning as well as how course learning translates into their own development towards learning goals; (d) e-portfolios are more flexible than exams in giving students both more control and more opportunities to succeed; and (e) e-portfolios are student centered.

A new survey is currently under preparation to be distributed in the spring of 2013. Additionally, in the spring of 2013 further rubric analysis will be conducted.

\section{References}

Ahn, J. (2004). Electronic portfolios: Blending technology, accountability \& assessment. $T$ H E Journal. $31(9)$.

Barrett, H. (2004). Electronic portfolios as digital stories of deep learning. Retrieved on 6/19/09 from: http://electronicportfolios.org/digistory/epstory.html

Buzzetto-More, N. (2006). Using electronic portfolios to build information literacy. Global Digital Business Review, 1(1), 6-11.

Buzzetto-More, N. (2009). Using web enabled project based learning to build information literacy. In. M. Leaning (Ed), Issues in information and media literacy. Santa Rosa, California: Informing Science Press.

Buzzetto-More, N. (2010). Applications of e-portfolios for value added assessment. In N. Buzzetto-More (Eds), The E-portfolio paradigm: Informing, educating, assessing, and managing with e-portfolios. Santa Rosa, California: Informing Science Press.

Buzzetto-More, N., \& Alade, A. (2008). The pentagonel electronic portfolio model. Journal of Information Technology Education, 7, 255-278.

Cooper, T., \& Love, T. (2007). Electronic portfolios in e-learning. In N. Buzzetto-More (Ed.). Advanced principles of effective e-learning. Santa Rosa: CA. Informing Science Press

Corbett-Perez, S., \& Dorman, S. (1999). Technology briefs. Journal of School Health, 69(6). 247.

Kuhlthau, C., \& Todd, R. (2007). Guided inquiry. Retrieved 9/10/07 from http://www.cissl.scils.rutgers.edu/guided_inquiry/implementation.html

Lorenzo, G., \& Ittelson, J. (2005a). An overview of e-portfolios. EduCause Learning Initiative. Retrieved 9/1/2007 from http://www.educause.edu/ir/library/pdf/ELI3002.pdf

Lorenzo, G., \& Ittelson, J. (2005b). Demonstrating and assessing student learning with e-portfolios. EduCause Learning Initiative Paper 3: 2005.

Paulson, F. L., \& Paulson, P. (1994). Assessing portfolios using the constructivist paradigm. In R. Fogarty (Eds). (1996) Student portfolios. Palatine: IRI Skylight Training \& Publishing

Paulson, F. L., Paulson, P. R., \& Meyer, C. (1991). What makes a portfolio a portfolio? Educational Leadership, 48(5), 60-63.

Renfrew, C., \& Bahn, P. (1996). Archaeology. Theories, methods, and practice. London: Thames and Hudson Ltd.

Stanford Encyclopedia of Philosophy. (1999). Artifact. Retrieved 1/22/2010 from: http://plato.stanford.edu/entries/artifact/\#1

Sweat-Guy, R., \& Buzzetto-More, N. (2007). A comparative analysis of common e-portfolio platforms and available features. Issues in Informing Science and Information Technology Education 5(1), 327-342. Retrieved 1/29/2010 from http://proceedings.informingscience.org/InSITE2007/IISITv4p327342Guy255.pdf

Venezsky, R. L., \& Oney, B. A. (2004). Creating and using portfolios on the alphabet superhighway. Retrieved August 5, 2009 from http://www.ash.udel.edu/ash/teacher/portfolio.html 
Vygotsky, L. (1978). Mind in society. London: Harvard University Press

Wang, S. (2009). Inquiry directed organization of e-portfolio artifacts for reflection. International Journal of E-Learning and Learning Objects, 5, 421-433. Retrieved 1/29/2010 from: http://www.ijello.org/Volume5/IJELLOv5p419-433Wang661.pdf

\section{Biography}

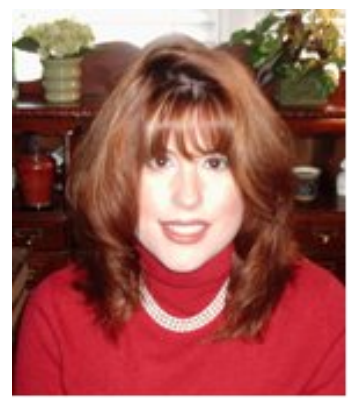

Dr. Nicole A. Buzzetto-More is an Associate Professor, program coordinator, and the Assurance of Learning Chair in the Department of Business at the University of Maryland Eastern Shore. She is also CoFounder of the UMES Office of Instructional Technology and developer of the Department of Business E-Portfolio Project. She received doctorate and masters degrees in communications and instructional technology from Columbia University and also holds a masters from the College of New Rochelle and a bachelors from Marist College. As a recognized assessment and e-learning expert, she is a frequent presenter at conferences across the globe. She is on the editorial board of several journals, has authored numerous publications in referred journals, and has been recognized with awards from the American Distance Education Consortium, Global Digital Business Association, and the Informing Science Institute. Recently, she was named a Fellow of the Informing Science Institute. She published two books in 2007, Principles of Effective Online Teaching and Advanced Principles of Effective ELearning. In early 2010 her third book The E-Portfolio Paradigm: Informing, Educating, Assessing, and Managing with E-Portfolios was published by the Informing Science Press. Her email address is nabuzzetto-more@umes.edu 